Waal, B.M.E. de, Batengurg, R. Design decisions in workflow management and quality of work. Internationqd journal of Information Systems and Change Management: 2009, 3(4), 359-374

\begin{tabular}{|l|l|}
\hline $\begin{array}{l}\text { Postprint } \\
\text { Version }\end{array}$ & 1.0 \\
\hline Journal website & $\underline{\underline{h t t p: / / w w w . i n g e n t a c o n n e c t . c o m / c o n t e n t / i n d / i j i s c m / 2009 / 00000003 / 00000004 / a ~}}$ \\
\hline Pubmed link & $\underline{\text { t00006 }}$ \\
\hline DOI & $10.1504 /$ IJISCM.2008.026711 \\
\hline
\end{tabular}

This is a NIVEL certified Post Print, more info at http://www.nivel.eu

\title{
Design decisions in workflow management and quality of work.
}

BENNY M.E. DE WAAL, RONALD BATENBURG

\begin{abstract}
:
In this paper, the design and implementation of a workflow management (WFM) system in a large Dutch social insurance organisation is described. The effect of workflow design decisions on the quality of work is explored theoretically and empirically, using the model of Zur Mühlen as a frame of reference. It was found among a total sample of 66 employees that there was no change in the experience of work quality before and after the introduction of the WFM system. There are however, significant differences in the quality of work before and after the WFM adoption if different functions are distinguished.
\end{abstract}

\section{INTRODUCTION}

Although workflow management (WFM) and WFM systems have been around for a long time (cf. Hollingsworth, 1994; Jablonski, 1995; Kobielus, 1997), its adoption and deployment are still a relevant topic. An editorial article of Information and Management shows that WFM over the years 1998-2005 is a stable issue. In this journal mostly three articles in an year (Palvia et al., 2007) are published on WFM. Most recently, WFM has been extended to the broader concept of Business Process Management (cf. Smith and Fingar, 2003; Weske et al., 2004).

The general premise of applying WFM is that the coordination of work can become easier, a higher quality of services is delivered, the work is executed more efficiently and the process becomes more flexible (Reijers et al., 2003). Despite the successes (Fischer, 2007), there are also many questions about the implementation of WFM. Most of the problems appear organisational, not technical. Moore (2002) for instance found that excessive activity automation and poor design of work assignment strategies are critical in workflow projects. In a study on the effects of workflow systems on organisations, Küng (2000) concludes that workflow design should be extended towards job design or even organisational design. He states that employees outside the IT department must play an active role from the beginning of a workflow project.

Apart from these studies, not much empirical research has been done on the organisational effects of WFM systems on the quality of work. An extensive line of research exists on the perceived usefulness and ease of use of IS/IT (cf. Konradt et al., 2006; Markus and Keil, 1994; Sabherwal et al., 2006; Venkatesh et al., 2003), but studies on changes in job content and its quality after IS/IT adoption are relatively scarce (Venkatesh et al., 2007). This study aims to advance the classic debate on upgrading and downgrading of skills and jobs in relation to IS/IT (Bresnahan et al., 2002; Grint and Woolgar, 1997; Zuboff, 1984), and to apply this specifically to WFM. In doing so, it may be possible to reveal how design decisions of a workflow system will result in changes in the quality of work of users.

In this paper, the theoretical perspectives of this study are described first. Next, the case study setting that makes it possible to investigate the design, implementation and use of a WFM system in a large Dutch social insurance organisation is described. Both qualitative and quantitative data have been collected and 
Waal, B.M.E. de, Batengurg, R. Design decisions in workflow management and quality of work. Internationad journal of Information Systems and Change Management: 2009, 3(4), 359-374

analysed, and this is also explained. This paper concludes with a discussion of the findings and suggestions for further research.

\section{THEORY, CONCEPTS AND DEFINITIONS}

\subsection{Defining the quality of work}

The quality of work can be defined and measured in several ways. One of the theoretical frameworks often used on the quality of work is the sociotechnical systems theory (Benders et al., 2000; De Sitter et al., 1997; Van Amelsvoort, 2000). According to this theory, the quality of work will be improved if jobs and organisations are designed according to certain principles. These principles are based on the strive to maintain a balance between problems in the work (control need) and possibilities of dealing with the problems (control capacity). If an employee has a problem, there should be enough possibilities to solve them conclusively. So, control capacity should be located there where the need for control arises. The benefit of a sociotechnically designed organisation, with regard to the quality of work, is that the workers perform not just one small, monotonous task in the whole production process (as in taylorised organisations), but that they perform, and are responsible for, a coherent set of tasks within a production cycle (Schouteten, 2001).

To define the concept of quality of work one can use Karasek's job demands model (Karasek, 1979) and Hacker's concept of complete tasks (Hacker, 1989). The balance between the sociotechnical concepts of control need (problems in the work) and control capacity (opportunities to deal with problems conclusively) is the same as Karasek described between job demands and decision latitude. The concept of complete tasks is used to describe the tasks in a job. A complete job consists of a coherent set of executing, preparing and supporting tasks, and varying levels of difficulty offer opportunities to learn on the job (self-development).

Based on this theoretical framework, six characteristics to define the quality of work are offered (Schouteten, 2001). These are:

1. Work variety: besides the primary executing tasks, a job should contain preparing and supporting tasks.

2. Learning opportunities: a job should contain a variety of difficult and easy tasks.

3. Workload: the job should consist of non-monotonous tasks.

4. Autonomy: the worker should be able to decide upon work pace, order and methods.

5. Relation with job environment: the ability to ask direct colleagues, superiors or other departments for help with problems.

6. Information of work: the worker should get enough information with respect to the work to be done.

Much empirical research has been done on the acceptance and validation labour-quality measurements (cf. Josten and Ester, 2005; Karasek, 1979, Kasarek and Theorell, 1990; Schouteten, 2001; Smulders, 2006). For the Netherlands, the NOVA-WEBA and VBBS model (Dhondt et al., 2002; Schouteten and Benders, 2004) are the leading instruments to measure quality of work that has been applied for over 20 years. For this study, these instruments were also used to measure the quality of work. The next section however, will first explain the policies to workflow design and the potential effect they can have on the quality of work.

\subsection{Defining workflow design policies}

There are many approaches to the development of WFM systems (cf. Russell et al., 2004a,b, 2006a,b; Sharp and McDermott, 2001; Van der Aalst and Van Hee, 2002; Van der Aalst et al., 2003). These approaches imply directly different ways on how to design workflow processes and hence the tasks of employees. From the perspective of the quality of work, two basic workflow design decisions can be distinguished:

1. how processes are designed from workflows (the process definition policy)

2. how users are connected to the activities that realise these processes (the assignment and synchronisation policy).

Section 2.3 explores how these policies, in particular their underlying decisions and subsequently their properties, will influence the quality of work. 
Waal, B.M.E. de, Batengurg, R. Design decisions in workflow management and quality of work. Internationad journal of Information Systems and Change Management: 2009, 3(4), 359-374

\subsection{The potential effects of workflow design policies on the quality of work}

Starting with the process definition policies, these determine the way the workflow is built and controlled by system features. Within the process definition domain, two basic decisions can be distinguished: the workflow structure and workflow control. Workflow structure is defined as the sequence and grouping of activities, and workflow control as the way case information has impact on the workflow. For each process definition decision, we can reason what the potential implications are for the quality of work.

For workflow structure, two specific properties can be distinguished:

1. Order of activities: implying the sequence in which activities are performed. If this is done in a logical way, a positive effect on information of work and relation with job environment is expected. The user knows what to do and can find the colleagues for help or information. In the arbitrary mode, the activities are not logically grouped. In this case a negative effect on information of work and relation with job environment is expected.

2. Wholeness of activities: as the way in which acts form a logical unit of work. In the complete mode, a positive effect on the two characteristics of work is expected. If this is not the case and acts are more distributed among the users then a negative affect is expected.

Workflow control, the second process definition decision, consists of three different properties. Their expected effects on labour quality are as follows:

1. Routing: the routing of a case can be done automatically or manually. In the automatic mode a negative effect on learning opportunities is expected, because the user is not involved in the decisions that have to be taken. In the manual mode it is the opposite. Therefore, a positive effect is expected.

2. Time triggering: this covers deadlines, reaction time and other warning signals. If this is automatic a positive effect on information on work is expected, because the users get information about the status of this work. If this is manual a negative effect is expected.

3. Authorised variance: this property defines the possibility to deviate from the workflow. If this is possible, then a positive effect on learning opportunities is expected in the dynamic mode. From the user's insight, he/she can decide which activity has to be performed. In the static mode, there is no possibility to deviate form the workflow. Here a negative effect on learning opportunities is expected.

Table 1 summarises the expectations elaborated above. Note that process definition policy is assumed to have effects on three of the six qualities of labour dimensions.

With regard to the assignment and synchronisation policies, it would be prudent to follow Zur Mühlen (2004a,b) as one of the few scholars who has described these decision aspects from a quality of work perspective. As indicated above, the label assignment policies for the distribution of activities between employees are used, and the label synchronisation policies for the way activities are allocated to individual employees.

With regard to the assignment policies, the two basic decisions are scheduling and task properties.

\section{[TABLE 1]}

Scheduling, by its turn, has three properties:

1. Planning of new work items: workflow enactment service is described when new activities become executable. If the WFM system is designed in such a way that this planning implies a 'net change', only the assignment for the new work item is determined. It is expected that this will lead to minor and probably positive workload and work variety changes. 'Re-planning' of new work items, on the other hand, will re-allocate many more work items including those that have not been started yet. In this situation, the system will merely take over, while the user will gain less control over his work. Therefore, a negative effect of this design decision on the workload and work variety is expected.

2. Time of notification: is to be considered as a key scheduling property. It is expected that employees will gain more control over their work if the system is designed in such a way that this 
Waal, B.M.E. de, Batengurg, R. Design decisions in workflow management and quality of work. Internationad journal of Information Systems and Change Management: 2009, 3(4), 359-374

is done upon availability. On the contrary, users of the WFM system will partly loose control if time notification is designed to be provided at the latest time. Consequently, two contrary effects from this decision with regard to time notification on workload and work variety are predicted.

3. Queuing of work items: a scheduling property. The decision to use a task pool is the decisive factor here, merely implying that if users can choose freely between available work items from such a pool, their quality of work will improve. In contrast, if the task pool is designed by the system as a queue (in which work items are selected by incoming order), employees will have less freedom to choose their task - which will eventually reduce their quality of work.

Task properties, the assignment policies' second decision, contains of two properties:

1. Activity execution: this property prescribes how many users may select a work item for execution. In the 'collaborative mode', work is assigned to a team which offers more responsibility to the users. The 'individual mode' in activity execution implies that the system allocates these activities directly to one individual user. Therefore, this option is expected to favour the employees' workload and work variety.

2. Decision hierarchy: defined as whether an activity can be passed on from an user to another delegate user. By 'final assignment' the system is designed in such a way that this is not possible, hence the user has less control over his work. If delegation is possible, this will contribute to his workload and work variety and hence increase the quality of work.

Table 2 summarises the expected effects of assignment policy on two of the six qualities of labour dimensions.

Finally, attention turns to the synchronisation policies that can be broken down into two basic decisions namely coordination and assignment.

Firstly, the coordination of pending work items can be considered in terms of two properties:

1. Coordination: as such. In the 'group negotiation' mode, users compete for the right to perform a particular activity. It is expected that this will increase job control, and subsequently autonomy. In the 'schedule' and 'hierarchy' mode, workflow enactment service (as introduced in the previous policy domain) assigns work items to the users. It is particularly expect that if the hierarchical option for this property is chosen, the employees' autonomy will decrease.

2. Allocation of work items: as a specific coordination action. One option is to design the 'manual mode' of the WFM system. This implies that only the pending activities are shown. If this is the case, the organisation determines the actual execution of pending activities mainly which provides decision space for employees and opportunities to improve their autonomy. If the 'fully' or 'partially automated mode' is chosen within the WFM design however, the system determines the users for an activity. Users will then have less control over the work which will reduce their autonomy.

\section{[TABLE 2]}

Secondly, the assignment decisions can be broken down into four properties:

1. Participant selection: this can be either designed as 'direct' or 'indirect' property.Direct refers to selection at the level of the individual user, indirect at the level of role, organisational position and organisational unit. In the indirect mode, users make the decision themselves, while in the direct mode the system does. Consequently, it is expected that the autonomy will improve in the first and diminish in the latter case.

2. Assignment specification: concerns the specification of the resource requirements to be designed with the WFM system as 'static' or 'dynamic'. Dynamic assignment take data from the current workflow case into account for the selection of qualified users. In static assignment, an activity is associated with one or more users which do not vary with different workflow cases. If the dynamic assignment option is chosen for the WFM design, more rules are embedded in the 
Waal, B.M.E. de, Batengurg, R. Design decisions in workflow management and quality of work. Internationad journal of Information Systems and Change Management: 2009, 3(4), 359-374

workflow system upon which users has no control. Therefore it is expected that implementation of the static option, not the dynamic option, will increase the employees' autonomy.

3. Assignment of work items: this can be executed in either a 'push' or 'pull' manner - can be interpreted as a similar basic design choice in terms of system versus user control. The push mode implies that the workflow system has control over the work items which will have a negative effect on the autonomy. Designed in the pull mode, the user determines the next work item at a convenient time.

4. Participant autonomy: this determines whether a user can refuse a work item or not. This directly addresses the choice within the WFM system design to create a control option for users over their work. This obviously implies that the employees' autonomy increases when the system allows them to reject assignments, and vice versa.

\section{[TABLE 3]}

\section{WFM AT A DUTCH SOCIAL INSURANCE ORGANISATION}

\subsection{Introduction}

An extensive case study was performed within a Dutch organisation for the execution of employee insurances. Since its foundation in 2002, as a result of a merger of five public organisations, the formal mission of this organisation was to stimulate people to work, and if work was impossible to provide a temporary income. The organisation is an independent policy agency that resorts under the Dutch Ministry of Social Affairs. It is a large administrative organisation that has a national task to execute several social security laws. The organisation controlled all administrative and financial processes to execute these laws, and was dedicated to control misuse and fraud. A second task was to realise the reintegration of (partly) unemployed and disabled employees. For this task the organisation collaborated with private health companies. The organisation had 18,196 employees in 2006. Since 2006, the number of employees was planned to be reduced drastically as a number of security processes would have been reallocated to the Dutch Tax Agency.

The research took place within the claim department, which is part of the divisions 'suitability for employment'. This division is divided into six regions. The basic principle of the organisational structure for each region is the main processes, namely the claim process and the payment process. The claim process happens only once and takes a long time, and the payment process consist of short cycles and happens periodically. Each process has his own department and the managers are responsible to a region manager.

The management style is based on delegation, but simultaneously, for reasons of efficiency, common use of systems and exchange of employees, the work must be done within established rules. On each organisational level, the planning and control cycles occur periodically. The focus of the claim department is to examine the medical and work capabilities and to judge the claims of the clients within the scope of the national laws.

Within the department over 4,000 employees are active.

In 2005, the organisation introduced a system to support the front office to integrate existing applications. As part of that, a WMF system was initiated. This WFM system was primarily aimed to streamline the core administrative processes of the social security laws within the claim organisation and improve its quality in terms of compliance with rules and procedures that are mostly of a legal kind. The system was specifically aimed to support the transition of information and tasks from one 'resource' to another. A resource can be a person (i.e. an employee) or a system (i.e. an application) as well. From the head start it was planned to deploy the WFM system among 600 employees. Data collection took place by studying project documentation, interviews and communication with project leaders and designers, and a survey among employees before and after implementation of the WFM system.

Besides achieving more efficiency and higher quality of services, the goal of the WFM project was to reach uniformity in case handling as well. To support this, the concept of teamwork was introduced. Teams were created by joining four different types of employees: team-support employees, process support employees, work/job consultants and insurance medical doctors. To ensure that the composition of the team fitted with the system, the size of a team was flexible. It was intended that a proper composition of the team will increase the (user) performance of the new WFM system. 
Waal, B.M.E. de, Batengurg, R. Design decisions in workflow management and quality of work. Internationad journal of Information Systems and Change Management: 2009, 3(4), 359-374

The project organisation consists of a steering group and among them project management. The steering group was supported by a sounding board and a project quality group. The steering group was responsible for the end result. The group was composed of business managers in the role of senior users, a manager of system development in the role of senior supplier, a representative of the user organisation, a project advisor and the project manager. The sounding board was responsible for the definition of the requirements of the user organisation, to set norms for and be applicable to the concerning quality demands and the acceptation of business products. The group consisted of managers and staff employees of the user organisation, one end user, quality advisor and development manager. The project quality group was responsible to monitor the quality aspects of the project and the deliveries. Members were quality advisors and domain experts. The responsibility of the project manager was to assure that the project delivers the right products within the appointments that have been made.

\subsection{Hypothesis}

To specify the expected effects of the WFM project on the characteristics of work at the organisation that was studied for this investigation, project documents and acquired additional information of project leaders and designers were analysed. Sources collected and analysed were mainly internal documents, such as project and design reports, steering meeting reports and user guides of the system. Several project members were also interviewed.

Based on a study of this data and information collected the process definition policy of the WFM project in this case could be specified. It was observed that user participation was explicitly part of the project planning and organisation. Therefore, the hypothesis was that all system workflow structure decisions are expected to be in favour of the employees' quality of work dimensions, information of work and relation with job environment. This hypothesis is also based on the notion that the design of the WFM system was specifically accompanied with the initiation of teamwork and cross-functional task organisation. In addition, based on project documents and statements of project leaders and users, the workflow control decisions are appointed to the system. So if Table 2 as presented in the previous theoretical section is applied on the case study organisation, the hypothesis is that the workflow control decisions of the WFM system have a negative effect on the employees' learning opportunities and a positive effect on their information of work.

From project documents and information of designers, the assignment and synchronisation policies behind the WFM project could also be specified. From the designers it appeared “... that according to the assignment and synchronisation policies no directives were appointed by the WFM system. In practice, before a case is started, the team decided which employees will treat the case. These decisions are recorded in the WFM system and employees determine which case will be executed.” All the properties were in control of the employees. If Tables 2 and 3 as presented in the previous section are applied, the hypothesis is that the assignment and synchronisation policies have a positive effect on workload, work variety and autonomy.

The hypotheses are summarised in Table 4.

\section{[TABLE 4]}

\section{[TABLE 5]}

\subsection{The survey among the WFM system users}

The questionnaire was primarily developed to measure the perceived quality of work of the targeted employees in 2005 and 2006. In 2006, a number of questions were added to query the user satisfaction of the new WFM system. Quality of work was measured through a total set of 43 items that address the six dimensions. As mentioned in the previous section, the items are based on validated scales for work satisfaction research.

The dimensions, number of items and an item example used in the questionnaire are presented in Table 5. Answer categories are standardised in four-point answer scales with 'full disagree' and 'fully agree' as it's minimum and maximum.

In 2005, just before the new WFM system was launched, a survey was conducted among a population of 94 employees at two locations (Amsterdam and Haarlem). Within these locations, the sampling was stratified according to the four main job categories that would jointly become team members, as the main 
Waal, B.M.E. de, Batengurg, R. Design decisions in workflow management and quality of work. Internationad journal of Information Systems and Change Management: 2009, 3(4), 359-374

users of the system (the team support employees, process support employees, work/job consultants and insurance medical doctors). One year later in 2006, as the WFM system was in use for some months, 89 employees of these 4 job categories were approached with a similar questionnaire and through a similar procedure. Due to work overload and technical problems with the system at the first locations, these respondents in 2006 were recruited at two different locations (Apeldoorn and Leeuwarden). Although some local differences cannot be excluded, it can be assumed that the employees at the different locations within the Netherlands have comparable work content and similar work conditions. This is due to the fact that the organisation executes formal, public tasks as a governmental social insurance organisation, and is equally shaped by what Dimaggio and Powell (1983) define as normative isomorphism.

Response rates were $45 \%$ and $30 \%$ in 2005 and 2006, respectively, resulting in a total dataset of 66 respondents (41 in 2005 and 25 in 2006). This is partly caused by the relatively high response rate among insurance medical doctors in 2005 (68\%), that dropped to 21\% in 2006. As was intended by sampling, the 2005 and 2006 response group does not significantly differ with regard to the main background characteristics such as age and gender. Work/job consultants are over-represented within both groups (31\% and $41 \%$ ) as they are the major users of the WFM system within the organisation.

The questionnaires were distributed through managers within the organisation.

Respondents were requested to complete it individually and carefully, stressing the anonymity of the survey. The indicated time of completion was $20 \mathrm{~min}$. Before sending out, the questionnaire was approved by the organisation and pre-tested with academic experts in the field of WFM and labour studies.

\section{RESULTS}

First, the two groups of employees that were queried in 2005 and 2006 were compared with regard to their answers on all the 43 different quality of work items. These items however, were designed to measure the six specific characteristics of labour quality as six clusters. Reliability analysis was performed to determine if the items for each of the six work quality characteristics can indeed be scaled to six latent variables. The Cronbach's alphas resulting from the six reliability analyses were as follows:

1. workload (8 items): 0.888

2. work variety (6 items): 0.732

3. learning opportunities (5 items): 0.859

4. autonomy (11 items): 0.834

5. relation with the job environment (7 items): 0.659

6. information of work (6 items): 0.774 .

According to the rules of thumb as indicated by Hair et al. (1998) and Nunnally and Burnstien (1994), the six Cronbach alphas are on an acceptable level. The next analyses are therefore based on these six aggregated variables, that is, work quality dimensions.

In practice, item scores were added and divided by the number of items to sustain the four-point scale and ease of interpretation. From the previous case study description, we hypothesise that the quality of work of the employees is higher in 2006 compared to 2005.

Results of the 2005/2006 group comparison are presented in Table 6 on a total sample level and broken down by the job category.

For all characteristics, the $t$-tests show that the two groups do not differ significantly in their perceived quality of work. If the $t$-tests are performed for all the 43 quality of labour items separately, the result remains with one exception. The item on learning experiences ("I believe I can reach something in my job") was significantly agreed more by the 2006 group compared with the 2005 group ( 2.88 versus 2.37 ).

If we break down the analyses for the four different job categories in our sample however, some significant differences in perceived work quality do appear (indicated in italics). Two significant results concern the process support employees that in 2006 experience less pace and time pressure compared to 2005 (1.99 versus 2.88), and at the same time less variation in their work ( 2.50 versus 3.02 ). The other significant difference appears for team support employees, who in 2006 experienced a better relation with the environment compared to 2005 (3.60 versus 2.90). For job consultants and medical insurance doctors, no significant differences before and after the introduction of the WFM system were found. 
Waal, B.M.E. de, Batengurg, R. Design decisions in workflow management and quality of work. Internationad journal of Information Systems and Change Management: 2009, 3(4), 359-374

\section{[TABLE 6]}

\section{[TABLE 7]}

An overview of the accepted or rejected hypothesis is presented in Table 7. For the total sample no positive effects were found on the design decisions. Only the process support employees have a positive effect on the characteristic workload and the team support employees on the characteristic relation with the job environment.

\section{CONCLUSION AND FURTHER RESEARCH}

In this research the effect of WFM systems, and its underlying workflow design decisions, on the quality of work were explored theoretically and empirically. Extending the work of Zur Mühlen (2004a,b), all relevant WFM design decisions and their properties and values were defined systematically and their potential effects on the work quality of employees were subsequently elaborated. This has resulted in an arguably new and complete mapping of workflow policies on labour quality.

The case study within a large Dutch social insurance organisation clearly illustrates that designing and implementing a WFM system implies many crucial (technological and organisational) decisions. Given the scope and impact of the WFM deployment, an advanced project organisation and management were required. A survey was held among a sample of employees before and after the introduction of the WFM system, in 2005 and 2006 respectively. As a first result, no basic change in the experience of work quality was measured. However, further analysis showed that there were significant differences before and after the WFM adoption if different job functions were distinguished. Positive changes were found for team support employees that reported a 'better' relation with the environment, and process support employees experienced lower pace and time pressure in 2006 compared to 2005. At the same time, however, the process support employees also experienced less variation in their work, about one year after the WFM implementation. No differences were found by job consultants and medical insurance doctors.

These results make sense, since both the team support and process support employees are the main users of the new WFM system. While for the team support employees the quality of work after introduction of the WFM system has improved, the process support employees appear to be confronted with a typical dual effect. While these employees experience less time pressure in their job after the introduction of the WFM system, their perceived variation in tasks decreased - which can be considered as a down-side effect in terms of work quality. This specific result actually resembles the internal differentiation hypothesis, showing that technology can have positive and negative effects on work quality at the same time (Steijn, 2001).

In practice, both the work quality of employees and the potential effect of a new WFM system are probably affected by more factors. One obvious factor is the limited period of time between the two points of measurement in this study. As is the case with many enterprise information systems, it takes a number of years before substantial organisational effects appear (Poston and Grabski, 2001). During the measurement after implementation it appeared that the system was still immature and not fully used. The old and new systems were used interchangeable and the new way to work in teams was not (yet) settled. Another interpretation draws back to the theory behind Orlikowski’s model (1992, 2000). Noting that the organisation is strongly effected by institutional properties, this might have blurred the WFM design decisions and its effects as described in our case study context. While the design/property decisions intentionally (originally) seemed to be in favour of the employees' quality of work, the institutional context might have caused a type of isomorphism that prevented users from actually experiencing an increase in their task control and autonomy. Again, measurements later in time can shed new light on this matter. Fortunately, the opportunity is there to follow this organisation and perform subsequent measurements on the quality of work among employees and the extended WFM system deployment in the near future.

\section{REFERENCES}

Benders, J., Doorewaard, H. and Poutsma, E. (2000) 'Modern socio-technology: set by de sitter', in Beyerlein, M.M. (Ed.), Work Teams: Past, Present, Future. Boston, Deventer: Kluwer Academic Publishers, pp.169-180. 
Waal, B.M.E. de, Batengurg, R. Design decisions in workflow management and quality of work. Internationad journal of Information Systems and Change Management: 2009, 3(4), 359-374

Bresnahan, T.F., Brynjolfsson, E. and Hitt, LM. (2002) 'Information technology, workplace organization and the demand for skilled labor: firm-level evidence', Quarterly Journal of

Economics, Vol. 117, No. 1, pp.339-376.

De Sitter, L.U., Den Hertog, J.F. and Dankbaar, B. (1997) 'From complex organizations with simple jobs to simple organizations with complex jobs', Human Relations, Vol. 50, pp.497-534.

Dhondt, S., Kraan, K. and Van Sloten, G. (2002) Work Organisation, Technology and Working Conditions. Dublin: European Foundation for the Improvement of Living and Working Conditions.

DiMaggio, P.J. and Powell, W.W. (1983) 'The iron cage revisited: institutional isomorphism and collective rationality in organizational fields', American Sociological Review, Vol. 48, No. 1, pp.147-160.

Fischer, L. (Ed.) (2007) 2007 Excellence in Practice: Moving the Goalposts. Lighthouse Point, FL: Future Strategies.

Grint, K. and Woolgar, S. (1997) The Machine at Work. Technology, Work and Organization. Cambridge: Polity Press.

Hacker, W. (1989) Vollständige vs. unvollständige Arbeitstätigkeiten. Arbeits- und Organisationspsychologie. München: Psychologie Verlags Union.

Hair, J.E., Anderson, R.E., Tatham, R.L. and Black, W.C. (1998) Multivariate Data Analysis. New Jersey: Prentice-Hall.

Hollingsworth, D. (1994) The Workflow Management Coalition Reference Model. Brussels: The Workflow Management Coalition.

Jablonski, S. (1995) 'On the complementarity of workflow management and business process modeling', SIGIOS Bulletin, Vol. 16, No. 1, pp.33-38.

Josten, E.J.C. and Ester, P. (2005) Quality of Work Life and Work Transitions. Tilburg: OSA-publication A213.

Karasek, R.A. (1979) 'Job demands, job decision latitude and mental strain: implications for job redesign', Administrative Science Quarterly, Vol. 24, pp.285-308.

Karasek, R. and Theorell, T. (1990) Healthy Work: Stress, Productivity, and the Reconstruction of Working Life. New York: Basic Books.

Kobielus, J.G. (1997) Workflow Strategies. Foster City, CA: IDG Books.

Konradt, U., Christophersen, T. and Schaeffer-Kuelz, U. (2006) 'Predicting user satisfaction, strain and system usage of employee self-services', Int. J. Human-Computer Studies, Vol. 64, pp.1141-1153.

Küng, P. (2000) 'The effects of workflow systems on organizations: a qualitative study', in Van der Aalst, W.M.P., Desel, J. and Oberwies, A. (Eds.), Business Process Management, Models,

Techniques, and Empirical Studies, Lecture Notes in Computer Science 1806. Berlin: Springer, pp.301316.

Markus, M.L. and Keil, M. (1994) 'If we build it, they will come: designing information systems that people want to use', Sloan Management Review, Vol. 35, No. 4, pp.11-25.

Moore, C. (2002) Common Mistakes in Workflow Implementations. Cambridge, MA: Giga Information Group.

Nunnally, J.C. and Bernstien, I.H. (1994) Psychometric Theory. New York: McGraw-Hill.

Orlikowski, W.J. (1992) 'The duality of technology: rethinking the concept of technology in organizations', Organization Science, Vol. 34, pp.398-427.

Orlikowski, W.J. (2000) 'Using technology and constituting structures: a practice lens for studying technology in organizations', Organization Science, Vol. 11, No. 4, pp.404-428.

Palvia, P., Pinjani, P. and Sibley, E.H. (2007) 'A profile of information systems research published in Information and Management', Information and Management, Vol. 44, No. 1, pp.1-11.

Poston, R. and Grabski, S. (2001) 'Financial impact of enterprise resource planning implementations', Int. J. Accounting Information Systems, Vol. 2, pp.271-294.

Reijers, H.A., Rigter, J.H.M. and Van der Aalst, W.M.P. (2003) 'The case handling case', Int. J. Cooperative Informative Systems, Vol. 12, No. 3, pp.365-391.

Russell, N., Ter Hofstede, A.H.M., Edmond, D. and Van der Aalst, W.M.P. (2004a) Workflow Data Patterns. Brisbane: Queensland University of Technology.

Russell, N., Ter Hofstede, A.H.M., Edmond, D. and Van der Aalst, W.M.P. (2004b) Workflow Resource Patterns. Eindhoven: Eindhoven University of Technology.

Russell, N., Ter Hofstede, A.H.M., Van der Aalst, W.M.P. and Mulyar, N. (2006a) 'Workflow controlpatterns: a revised view', Available at www.BPMcenter.org (accessed 15/10/2008).

Russell, N., Van der Aalst, W.M.P. and Ter Hofstede, A.H.M. (2006b) 'Exception handling patterns in process-aware information systems', Available at: www.BPMcenter.org. Accessed on 15 October 2008.

Sabherwal, R., Jeyaraj, A. and Chowa, C. (2006) 'Information systems success: individual and organizational determinants', Management Science, Vol. 52, No. 12, pp.1849-1864.

Schouteten, R. and Benders, J. (2004) 'Lean production assessed by Karasek's job demand job control model', Economic and Industrial Democracy, Vol. 25, No. 3, pp.347-373. 
Waal, B.M.E. de, Batengurg, R. Design decisions in workflow management and quality of work. Internationed journal of Information Systems and Change Management: 2009, 3(4), 359-374

Schouteten, R.L.J. (2001) Balances in Well-being at Work: Measurements, Determinants and Improvements of the Quality of Working Life. Cappelle a/d ljssel: Labyrint Publication.

Sharp, A. and McDermott, P. (2001) Workflow Modeling: Tools for Process Improvement and Application Development. Norwood: Artech House.

Smith, H. and Fingar, P. (2003) Business Process Management: the Third Wave. Tampa, FL: MeghanKiffer Press.

Smulders, P.G.W. (2006) Worklife in the Netherlands. Hoofddorp: TNO Work and Employment.

Steijn, B. (2001) 'Work systems, quality of working life and attitudes of workers. An empirical study towards the effects of team and non-teamwork', New Technology, Work, and Employment, Vol. 16, No. 3, pp.191203.

Van Amelsvoort, P. (2000) The Design of Work and Organisation, The Modern Socio-technical Systems Approach. Vlijmen: ST groep.

Van der Aalst, W.M.P., Ter Hofstede, A.H.M., Kiepuszewski, B. and Barros A.P. (2003) 'Workflow patterns', Distributed and Parallel Databases, Vol. 14, No. 3, pp.5-51.

Van der Aalst, W.M.P. and Van Hee, K.M. (2002) Workflow Management: Models, Methods, and Systems. Cambridge, MA: MIT Press.

Venkatesh, V., Davis, F.D. and Morris, M.G. (2007) 'Dead or alive? The development, trajectory and future of technology adoption research', Journal of the Association for Information Systems, Vol. 8, No. 4, pp.267-286.

Venkatesh, V., Morris, M.G. and Davis, G.B. (2003) 'User acceptance of information technology: toward a unified view', MIS Quarterly, Vol. 27, pp.425-479.

Weske, M., Van der Aalst, W.M.P. and Verbeek, H.M.W. (2004) 'Advances in business process management', Data and Knowledge Engineering, Vol. 50, pp.1-8.

Zuboff, S. (1984) In the Age of the Smart Machine. The Future of Work and Power, New York: Basic Books. Zur Mühlen, M. (2004a) Workflow-Based Process Controlling. Berlin: Logos Verlag.

Zur Mühlen, M. (2004b) 'Organizational management in workflow applications - issues and perspectives', Information Technology and Management Journal, Vol. 5, No. 3, pp.271-291.

\section{TABLES}

Table 1 Process definition policies and expected effect on information of work, relation with job environment and learning opportunities

\begin{tabular}{|c|c|c|c|c|c|}
\hline \multirow[b]{2}{*}{ Decision } & \multirow[b]{2}{*}{ Property } & \multirow[b]{2}{*}{ Value } & \multicolumn{3}{|c|}{ Expected effect on: } \\
\hline & & & $\begin{array}{l}\text { Information } \\
\text { of work }\end{array}$ & $\begin{array}{l}\text { Relation with } \\
\text { job environment }\end{array}$ & $\begin{array}{l}\text { Learning } \\
\text { opportunities }\end{array}$ \\
\hline \multirow{4}{*}{$\begin{array}{l}\text { Workflow } \\
\text { structure }\end{array}$} & \multirow{2}{*}{$\begin{array}{l}\text { Order of } \\
\text { activities }\end{array}$} & Logical & Positive & Positive & \\
\hline & & Arbitrary & Negative & Negative & \\
\hline & \multirow{2}{*}{$\begin{array}{l}\text { Wholeness } \\
\text { of activities }\end{array}$} & Complete & Positive & Positive & \\
\hline & & Distributed & Negative & Negative & \\
\hline \multirow{6}{*}{$\begin{array}{l}\text { Workflow } \\
\text { control }\end{array}$} & \multirow[t]{2}{*}{ Routing } & Automatic & & & Negative \\
\hline & & Manual & & & Positive \\
\hline & \multirow{2}{*}{$\begin{array}{l}\text { Time } \\
\text { triggering }\end{array}$} & Automatic & Positive & & \\
\hline & & Manual & Negative & & \\
\hline & \multirow{2}{*}{$\begin{array}{l}\text { Authorised } \\
\text { variance }\end{array}$} & Static & & & Negative \\
\hline & & Dynamic & & & Positive \\
\hline
\end{tabular}


Table 2 Assignment policies and expected effect on workload and work variety

\begin{tabular}{|c|c|c|c|c|}
\hline \multirow[b]{2}{*}{ Decision } & \multirow[b]{2}{*}{ Property } & \multirow[b]{2}{*}{ Value } & \multicolumn{2}{|c|}{ Expected effect on } \\
\hline & & & Workload & Work variety \\
\hline \multirow[t]{8}{*}{ Scheduling } & \multirow{2}{*}{$\begin{array}{l}\text { Planning of new } \\
\text { work items }\end{array}$} & Net change & Positive & Positive \\
\hline & & Re-planning & Negative & Negative \\
\hline & \multirow[t]{3}{*}{ Time of notification } & Upon availability & Positive & Positive \\
\hline & & $\begin{array}{l}\text { Between availability } \\
\text { and latest start time }\end{array}$ & $\begin{array}{l}\text { Positive or } \\
\text { negative }\end{array}$ & $\begin{array}{l}\text { Positive or } \\
\text { negative }\end{array}$ \\
\hline & & At latest start time & Negative & Negative \\
\hline & \multirow{3}{*}{$\begin{array}{l}\text { Queuing of new } \\
\text { work items }\end{array}$} & Pool & Positive & Positive \\
\hline & & Combination & $\begin{array}{l}\text { Positive or } \\
\text { negative }\end{array}$ & $\begin{array}{l}\text { Positive or } \\
\text { negative }\end{array}$ \\
\hline & & Queue & Negative & Negative \\
\hline \multirow{4}{*}{$\begin{array}{l}\text { Task } \\
\text { properties }\end{array}$} & \multirow[t]{2}{*}{ Activity execution } & Collaborative & Positive & Positive \\
\hline & & Individual & Negative & Negative \\
\hline & \multirow[t]{2}{*}{ Decision hierarchy } & Delegation possible & Positive & Positive \\
\hline & & Final assignment & Negative & Negative \\
\hline
\end{tabular}

Table 3 Synchronisation policies and expected effect on autonomy

\begin{tabular}{|c|c|c|c|}
\hline \multirow[b]{2}{*}{ Decision } & \multirow[b]{2}{*}{ Property } & \multirow[b]{2}{*}{ Value } & Expected effect on: \\
\hline & & & Autonomy \\
\hline \multirow[t]{6}{*}{ Coordination } & Coordination & Group negotiation & Positive \\
\hline & & Schedule & Positive or negative \\
\hline & & Hierarchy & Negative \\
\hline & Allocation of work items & Manual & Positive \\
\hline & & Partially automated & Positive or negative \\
\hline & & Fully automated & Negative \\
\hline \multirow[t]{9}{*}{ Assignment } & Participant selection & Indirect & Positive \\
\hline & & Direct & Negative \\
\hline & Assignment specification & Static & Positive \\
\hline & & Dynamic & Negative \\
\hline & Assignment of work items & Pull & Positive \\
\hline & & Combination & Positive or negative \\
\hline & & Push & Negative \\
\hline & Participant autonomy & Rejection of assignment possible & Positive \\
\hline & & Assignment is final & Negative \\
\hline
\end{tabular}


Waal, B.M.E. de, Batengurg, R. Design decisions in workflow management and quality of work. Internationad journal of Information Systems and Change Management: 2009, 3(4), 359-374

Table 4 Design decisions and the expected effect on characteristics of work

\begin{tabular}{|c|c|c|c|c|c|c|}
\hline Decision & Workload & Work variety & Autonomy & $\begin{array}{l}\text { Learning } \\
\text { opportunities }\end{array}$ & $\begin{array}{l}\text { Information } \\
\text { of work }\end{array}$ & $\begin{array}{l}\text { Relation with job } \\
\text { environment }\end{array}$ \\
\hline $\begin{array}{l}\text { Workflow } \\
\text { structure }\end{array}$ & & & & & Positive & Positive \\
\hline $\begin{array}{l}\text { Workflow } \\
\text { control }\end{array}$ & & & & Negative & Positive & \\
\hline Scheduling & Positive & Positive & & & & \\
\hline $\begin{array}{l}\text { Task } \\
\text { properties }\end{array}$ & Positive & Positive & & & & \\
\hline Coordination & & & Positive & & & \\
\hline Assignment & & & Positive & & & \\
\hline
\end{tabular}

Table 5 Characteristics to measure quality of work among the employees in 2005 and 2006

\begin{tabular}{llc}
\hline Characteristics & Example item & Number of items \\
\hline 1 Workload & "I need to work with strong pace" & 8 \\
2 Work variety & "I perform the same tasks over again" & 6 \\
3 Learning opportunities & "My work provides opportunities for independent & 5 \\
& $\begin{array}{l}\text { acting and thinking" } \\
\text { "I determine the way I work myself" }\end{array}$ & 11 \\
5 Relation with the job & $\begin{array}{l}\text { "During my work I have direct contact with my } \\
\text { environment }\end{array}$ & 7 \\
6 Information of work & "I have sufficient information to perform my tasks" & 6 \\
\hline
\end{tabular}


Table 6 The perceived quality of work by respondents in 2005 and 2006 by job category

\begin{tabular}{|c|c|c|c|c|c|c|}
\hline \multirow[b]{2}{*}{ Quality of work characteristic } & \multicolumn{3}{|c|}{ Mean scores } & \multicolumn{3}{|c|}{$\begin{array}{c}\text { Two sided t-test of equality of } \\
\text { means }\end{array}$} \\
\hline & 2005 & 2006 & $\begin{array}{c}\text { Difference } \\
2005 / \\
2006\end{array}$ & $t$-Values & $\begin{array}{c}\text { Degrees } \\
\text { of } \\
\text { freedom }\end{array}$ & p-Values \\
\hline \multicolumn{7}{|l|}{ Workload } \\
\hline Total sample & 2.91 & 2.71 & -0.20 & 1.44 & 64 & 0.16 \\
\hline Team support employees only & 2.83 & 2.59 & -0.24 & 0.38 & 7 & 0.71 \\
\hline Process support employees only & 2.88 & 1.99 & -0.89 & 4.02 & 12 & 0.00 \\
\hline Job consultants only & 2.85 & 2.84 & -0.01 & 0.08 & 20 & 0.94 \\
\hline Medical insurance doctors only & 3.00 & 3.12 & 0.12 & -0.50 & 19 & 0.63 \\
\hline \multicolumn{7}{|l|}{ Work variety } \\
\hline Total sample & 2.89 & 2.86 & -0.03 & 0.29 & 64 & 0.77 \\
\hline Team support employees only & 3.17 & 2.94 & -0.22 & 0.46 & 7 & 0.66 \\
\hline Process support employees only & 3.02 & 2.50 & -0.52 & 2.65 & 12 & 0.02 \\
\hline Job consultants only & 3.05 & 2.93 & -0.13 & 0.68 & 20 & 0.50 \\
\hline Medical insurance doctors only & 2.62 & 2.92 & 0.29 & -1.55 & 19 & 0.14 \\
\hline \multicolumn{7}{|l|}{ Learning opportunities } \\
\hline Total sample & 2.61 & 2.71 & 0.09 & -0.57 & 64 & 0.57 \\
\hline Team support employees only & 2.80 & 2.58 & -0.23 & 0.36 & 7 & 0.73 \\
\hline Process support employees only & 2.66 & 2.60 & -0.06 & 0.23 & 12 & 0.82 \\
\hline Job consultants only & 2.72 & 2.94 & 0.22 & -0.79 & 20 & 0.44 \\
\hline Medical insurance doctors only & 2.45 & 2.57 & 0.11 & -0.33 & 19 & 0.75 \\
\hline \multicolumn{7}{|l|}{ Autonomy } \\
\hline Total sample & 2.68 & 2.79 & 0.11 & -1.06 & 65 & 0.29 \\
\hline Team support employees only & 2.87 & 2.91 & 0.04 & -0.18 & 8 & 0.86 \\
\hline Process support employees only & 2.66 & 2.84 & 0.18 & -1.18 & 12 & 0.26 \\
\hline Job consultants only & 2.93 & 2.82 & -0.12 & 0.64 & 20 & 0.53 \\
\hline Medical insurance doctors only & 2.41 & 2.59 & 0.18 & -0.82 & 19 & 0.42 \\
\hline \multicolumn{7}{|l|}{ Relation with the job environment } \\
\hline Total sample & 3.18 & 3.17 & -0.01 & 0.10 & 65 & 0.92 \\
\hline Team support employees only & 2.90 & 3.60 & 0.70 & -4.34 & 8 & 0.00 \\
\hline
\end{tabular}


Table 6 The perceived quality of work by respondents in 2005 and 2006 by job category (continued)

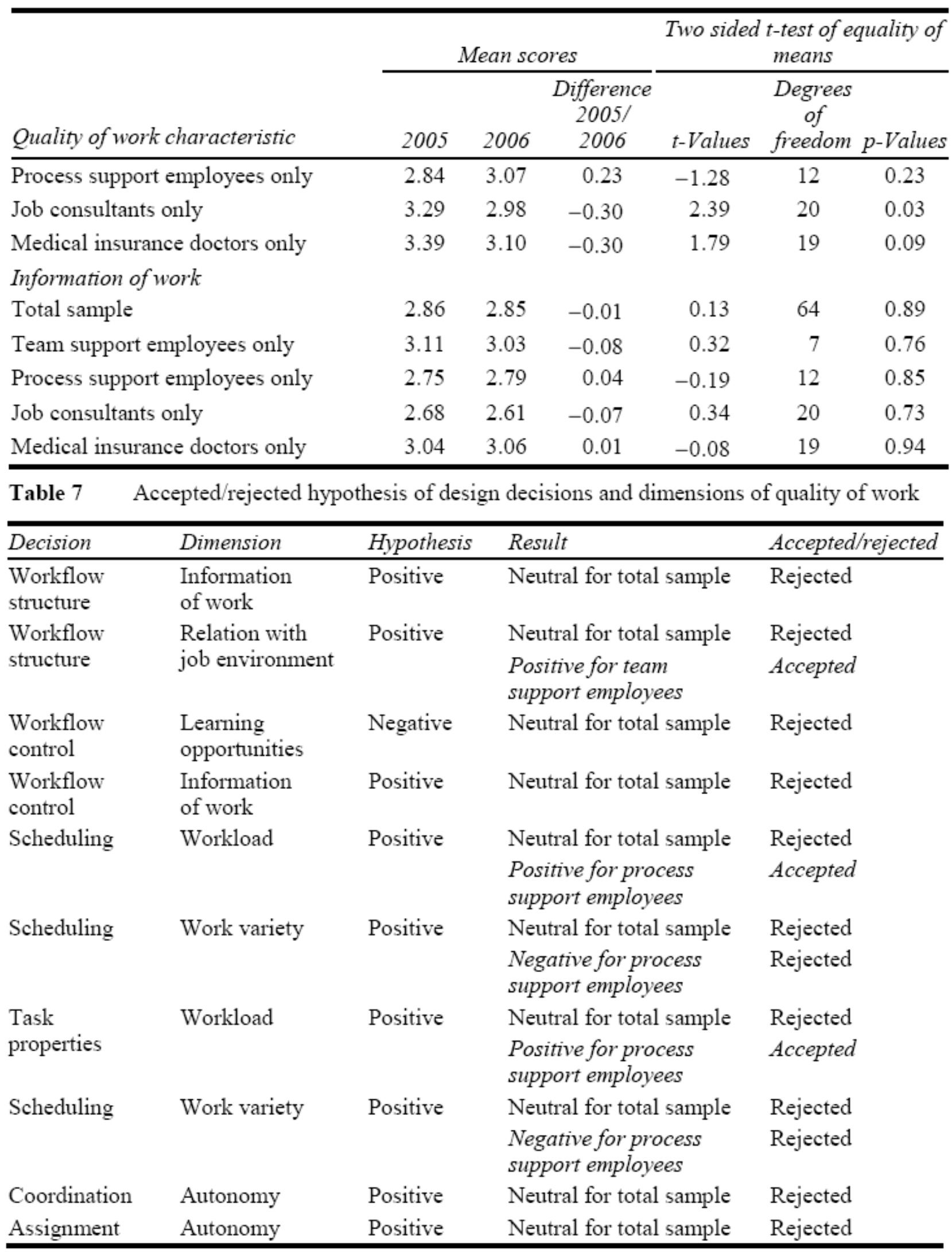

